\title{
Diagnóstico da qualidade de água ao longo do estuário do rio Itajaí-Açu, SC.
}

\section{Diagnosis of water quality along the Itajaí-Açu river estuary, SC}

Cátia Milene Ehlert Von-Ahn ${ }^{1}$ e Jurandir Pereira Filho ${ }^{2}$

\author{
${ }^{1}$ Universidade do Vale do Itajaí, Laboratório de Oceanografia Química e Poluição Marinha - CTTMAR, Itajaí, SC, Brasil \\ catia.milene@yahoo.com.br
}

\footnotetext{
${ }^{2}$ Universidade do Vale do Itajaí, Laboratório de Oceanografia Química e Poluição Marinha - CTTMAR, Itajaí, SC, Brasil jurandir@univali.br
}

\section{RESUMO}

O presente estudo consistiu na avaliação espacial e temporal da qualidade de água ao longo do estuário do rio Itajaí-Açu, entre os anos de 2003 a 2011. Foram avaliados os parâmetros físico-químicos, nutrientes inorgânicos dissolvidos, COP, DBO, , Cla-a, SS e Coliformes fecais. O estuário foi dividido em três segmentos (alto, médio e baixo). Na avaliação espacial os altos valores de SS (82,7 $\pm 114 \mathrm{mg} / \mathrm{l}), \mathrm{DBO}_{5}(2,5 \pm 0,9 \mathrm{mg} / \mathrm{l})$ e COP (203,8 $\left.\pm 230 \mu \mathrm{M}\right)$ se associaram a regiões de maior população e área agrícola, sendo estes encontrados em maior concentração no alto estuário. Elevaçães de $\mathrm{NH}_{4}^{+}$no baixo

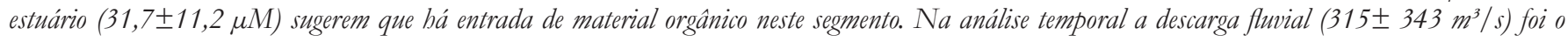
principal agente responsável pelas alterações das variáveis de qualidade de água se relacionando fortemente ao SS e ao COP. Ao comparar as variáveis com a resolução CONAMA 357/05 observou-se que as maiores inconformidades foram observadas no baixo estuário, em periodos de baixa descarga fluvial.

Palavras Chave: Descarga fluvial. Litoral norte de Santa Catarina. Uso agrícola. Urbanização

\begin{abstract}
:
The present study consisted in the evaluation of spatial and temporal quality of the water in the Itajai-Acu river estuary, from 2003 to 2011 . We evaluated physicochemical parameters, dissolved inorganic nutrients, POC, BOD, Cla-a, SS and fecal coliforms. The estuary was divided in three segments (bigh,

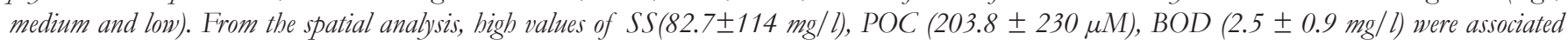
with regions with high population and agricultural area., these parameters being found at higher concentrations in the high estuary. The high levels of $\mathrm{NH}_{4}^{+}(31,7 \pm 11,2 \mu \mathrm{M})$ suggest an input of organic material in the lower estuary. In temporal analysis a strong influence of the river discharge (315士 343 $\mathrm{m}^{3} / \mathrm{s}$ ) on the system was found, strongly related to SS and POC. By comparing these values with CONAMA Resolution 357/05, our data suggest that the main non-conformities were observed in the lower estuary during periods of low river discharge.
\end{abstract}

Keywords: River discharge. North coast of Santa Catarina. Agricultural use. Urbanization 


\section{INTRODUÇÃO}

O termo estuário é utilizado para indicar a região interior de um ambiente costeiro, onde ocorre o encontro das águas fluviais com a água marinha transportada pelas correntes de maré se estendendo até o limite da influência da maré (MIRANDA et al., 2002). Este ambiente geralmente é dividido em três setores: o estuário inferior ou marinho com ligação livre para o oceano; estuário médio sujeito a intensa mistura da água do mar com a fluvial; e estuário superior ou fluvial caracterizado por água doce, porém sujeito a influência da maré (DIONNE, 1963). Com o resultado da crescente pressão sobre os ecossistemas costeiros de todo mundo, as cargas de sedimento em suspensão, nutrientes, produtos químicos oriundos de indústrias, pesticidas entre outros, causam declínios na qualidade de água dos rios e estuários, podendo exercer influência também sobre a região costeira (SCHAFFELKE et al., 2011).

Apesar de mostrar um padrão de desenvolvimento econômico elevado para a realidade brasileira, o estado de Santa Catarina tem os mais baixos percentuais de cobertura de serviços de coleta e tratamento de efluentes, apresentando a bacia hidrográfica do rio Itajaí-Açu, uma situação crítica no que se refere a coleta e tratamento de efluentes. Em função disso, alguns municípios iniciaram a implantação de rede coletora e instalação de sistema de tratamento de efluentes a partir de 2009. Essa implantação e o aumento da cobertura dos municípios da bacia podem resultar em melhoria gradual da qualidade dos corpos d'agua na região.

A porção final da bacia do Rio Itajaí-Açu constitui um dos mais importantes polos industriais e urbano do Estado, cujas atividades principais são a industrial têxtil, metal mecânico, papeleira, além das indústrias de beneficiamento do pescado no município de Itajaí e Navegantes (BELLOTTO et al., 2009). Nas margens do estuário estão situadas cerca 70 indústrias de pescado, tornando a cidade de Itajaí o maior porto pesqueiro do Brasil (PEREIRA FILHO et al., 2010). Próximo à foz encontra-se também um elevado grau de ocupação das margens por cais de atracação de embarcação de pesca, estaleiros, portos e orla urbana das cidades de Itajaí e Navegantes (SCHETTINI; TRUCCOLO, 2009).

Programas de monitoramento vêm sendo desenvolvidos e demonstraram que a qualidade química da água sofre deterioração principalmente na porção final do estuário, tendo como causa as ocupações de suas margens (SILVA; PEREIRA FILHO, 2010). Assim, esse trabalho tem como objetivo fazer um diagnóstico da qualidade de água ao longo do estuário do Rio Itajaí-Açu, mostrando como ocorre sua variação desde sua porção fluvial até a região de sua desembocadura, assim como sua evolução entre os anos de 2003 a 2011. Esse diagnóstico pretende servir como um panorama da qualidade de água na região, antes da implantação de sistema de coleta e tratamento de efluente nas cidades da bacia.

\section{MATERIAL E MÉTODOS}

\section{Área de estudo}

A bacia do rio Itajaí-Açu é a maior bacia da vertente atlântica do Estado de Santa Catarina com uma área de 15.500 $\mathrm{km}^{2}$, correspondendo cerca de $15 \%$ da área do estado, compreendendo em média de 50 municípios com uma população de cerca de1 milhão de habitantes. Ela é dividida em três regiões: o alto, médio e baixo vale. $\mathrm{O}$ alto vale é representado por atividades agrícolas colaborando com uma grande quantidade de efluentes contendo defensivos agrícolas ou dejetos de animais, o médio vale compreende atividades industriais contribuindo com efluentes químicos (SILVA; PEREIRA FILHO, 2010). Já o baixo vale, além de receber a drenagem da bacia possui diversos terminais portuários e indústrias pesqueiras em suas margens e

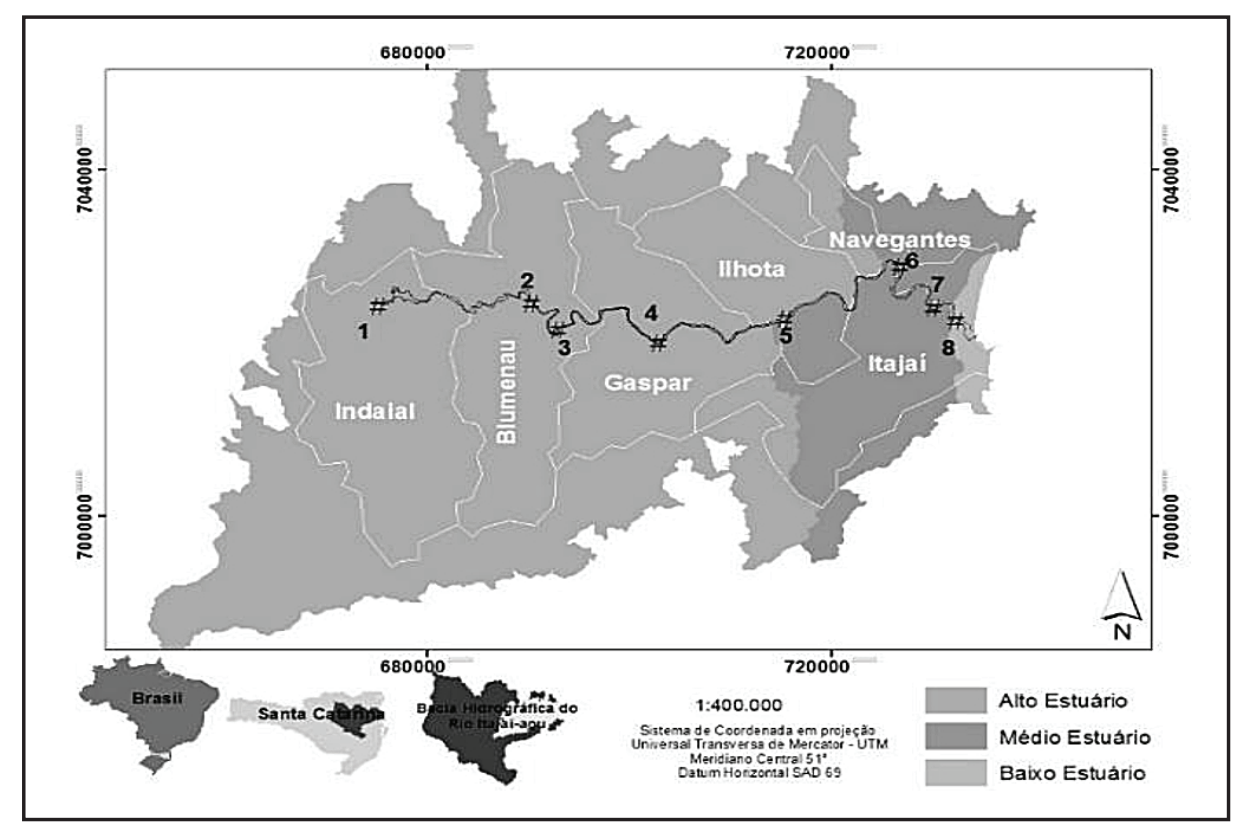

Figura 1 - Área de estudo com as estações amostrais 
é onde está localizado o estuário do rio Itajaí-Açu.

O estuário do rio Itajaí-Açu está localizado nas coordenadas $26^{\circ} 54,7^{\prime} \mathrm{S}$ e $48^{\circ} 381^{\prime}$ 'W com extensão de aproximadamente $70 \mathrm{~km}$ e espelho da água de $14 \mathrm{~km}^{2}$. O estuário é classificado em relação a sua hidrodinâmica como altamente estratificado ou de tipo cunha salina (SCHETTINI, 2002). A área de drenagem do estuário corresponde a uma área de aproximadamente $3.150 \mathrm{~km}^{2}$ o que equivale a $21 \%$ do total da bacia hidrográfica do Rio Itajaí-Açu. Indaial foi determinada como limite superior por ser a primeira cidade que não sofre influência da maré e é também o local onde é feita a medição diária da descarga fluvial do rio Itajaí-Açu. No outro extremo estão o município de Itajaí e Navegantes separados pelo baixo estuário do rio Itajaí-Açu, na região costeira.

A descarga fluvial média, calculada com os dados diários de descarga de 1934 a 1998, é de $228 \pm 282 \mathrm{~m}^{3} \cdot$ ss- $^{1}$ e a altura da maré astronômica regional é de $0,8 \mathrm{~m}$ (SCHETTINI; TRUCOLLO, 2009). A partir das definições propostas por Dionne (1963) sobre as subdivisões para estuários, Schettini (2002) propôs subdivisões para o estuário do rio Itajaí-Açu: o alto estuário sendo a região compreendida entre os municípios de Indaial e Ilhota; médio estuário de Ilhota até o ponto próximo a confluência do estuário com o Rio Itajaí-Mirim e baixo estuário sendo deste ponto até a foz (Figura 1).

\section{Uso do Solo}

O conhecimento do uso e ocupação da região em estudo se torna um item de grande importância para as possíveis interpretações dos dados de qualidade de água. Por isso realizouse um levantamento dos principais usos na área em estudo, a partir de dados do IBGE. Entre os usos e a ocupação do solo que mais podem influenciar na qualidade de água estão o desenvolvimento urbano e as atividades de agricultura (PEREIRA FILHO et al., 2010). A tabela 1 mostra a população da área em estudo e da bacia hidrográfica. O alto estuário compreende os municípios de Indaial, Blumenau, Gaspar e Ilhota, o médio e baixo estuário compreende os municípios de Itajaí e Navegantes. Observa-se que a população da área em estudo corresponde a cerca de 56\% da população total da bacia (Tabela 1) sendo que a área equivale a apenas $21 \%$, compondo um forte indício da ação antrópica nesta região.

Tabela 1 - População dos municípios da margem do estuário e da bacia hidrográfica

\begin{tabular}{c|c|c|c}
\hline Ano & \multicolumn{2}{|c|}{$\begin{array}{c}\text { População - Estuário } \\
\text { (hab.) }\end{array}$} & $\begin{array}{c}\text { População } \\
\text { Bacia (hab.) }\end{array}$ \\
\hline & $\begin{array}{c}\text { Alto } \\
\text { estuário }\end{array}$ & $\begin{array}{c}\text { Médio/Baixo } \\
\text { estuário }\end{array}$ & \\
\hline $\mathbf{2 0 0 0}$ & 358.990 & 186.811 & 996.443 \\
\hline $\mathbf{2 0 0 7}$ & 404.638 & 215.856 & 1.120 .350 \\
\hline $\mathbf{2 0 1 0}$ & 434.201 & 243.929 & 1.212 .494 \\
\hline
\end{tabular}

Fonte: IBGE (2013)

Em relação a urbanização o alto estuário se destaca por conter o maior número de habitantes.Esta região representa cerca de $85 \%$ da área total em estudo englobando o município de Blumenau, que possui o maior número de habitantes dos municípios da bacia. No médio e baixo estuário está situado o município de Itajaí que possui cerca de 200 mil habitantes (IBGE, 2013). Durante o período em estudo a população aumentou a uma taxa de $2 \%$ e $3 \%$ nas regiões do alto e médio/ baixo estuário respectivamente. A população da bacia também apresentou aumento a uma taxa de $2 \%$.

Em relação a agricultura, nos municípios que margeiam o estuário ocorreram oscilações na área agrícola com um ligeiro aumento entre 2004 e 2011, em torno de 1000 ha (Tabela 2), sendo o município de Gaspar e Indaial com a maior agrícola da área em estudo. Ao contrário do estuário a área agrícola da bacia apresentou decaimento durante o período em estudo (Tabela 2).

Tabela 2 - Área da agricultura para a região do estuário e de toda a bacia

\begin{tabular}{|c|c|c|c|}
\hline \multirow[t]{2}{*}{ Ano } & $\begin{array}{c}\text { Agricultura } \\
\text { Bacia (ha) }\end{array}$ & \multicolumn{2}{|c|}{$\begin{array}{l}\text { Agricultura } \\
\text { Estuário (ha) }\end{array}$} \\
\hline & & $\begin{array}{l}\text { Médio } \\
\text { Estuário }\end{array}$ & $\begin{array}{c}\text { Baixo } \\
\text { Estuário }\end{array}$ \\
\hline 2004 & & 9.482 & 3.371 \\
\hline 2005 & & 10.296 & 3.493 \\
\hline 2006 & 164.642 & 10.411 & 3.938 \\
\hline 2007 & 157.383 & 11.038 & 4.039 \\
\hline 2008 & 154.976 & 10.808 & 3.920 \\
\hline 2009 & 150.268 & 8.841 & 3.411 \\
\hline 2010 & 147.495 & 7.634 & 3.994 \\
\hline 2011 & & 9.460 & 4.095 \\
\hline
\end{tabular}

Fonte: IBGE (2013)

A rizicultura é a cultura de maior destaque na área de estudodevido a classificação geomorfológica do estuário ser de planície costeira. A declividade do estuário é de $0,03 \%$ e à montante de Blumenau aumenta para 0,40\% (SCHETTINI, 2002) sendo isto um fator importante para escolha do terreno para o cultivo da planta. As microrregiões de Blumenau e Itajaí estão em terceiro e quarto lugar no volume produzido de arroz correspondendo 7,1\% e 7,2\% respectivamente do total produzido no estado. (EPAGRI, 2012). A rizicultura é concentrada nas margens do estuário fazendo o uso da água para a irrigação das lavouras. A água é captada ao longo de todo o ciclo do arroz e é parcialmente devolvida para o estuário após ser utilizada (SILVA; PEREIRA FILHO, 2010).

\section{MÉTODOS}

Desde 1999 um programa de monitoramento ambiental vem sendo realizado na porção final da bacia do rio Itajaí-Açu. O presente trabalho foi realizado a partir de dados secundários compilados de trabalhos já realizados no estuário (PEREIRA FILHO, 2006; PEREIRA FILHO et al., 2010; SILVA; PEREIRA FILHO, 2010) e de dados do laboratório de oceanografia química da UNIVALI ainda não publicados. Durante as campanhas de monitoramento foram feitas medições de variáveis físico-químicas 
Tabela 3 - Metodologia da determinação das variáveis de qualidade de água

\begin{tabular}{|c|c|}
\hline Parâmetro & Metodologia \\
\hline Nitrogênio & Método Colorimétrico. \\
\hline Amoniacal $\left(\mathrm{NH}_{4}{ }^{+}\right)$ & $\begin{array}{l}\text { Determinado pela formação do } \\
\text { complexo colorido azul de } \\
\text { indofenol, }\end{array}$ \\
\hline Nitrito $\left(\mathrm{NO}_{2}^{-}\right)$ & $\begin{array}{l}\text { Método Colorimétrico. Baseado na } \\
\text { reação de Griess. }\end{array}$ \\
\hline Nitrato $\left(\mathrm{NO}_{3}{ }^{-}\right)$ & $\begin{array}{l}\text { Método colorimétrico. } \\
\text { Determinado como nitrito, após a } \\
\text { passagem por uma coluna redutora } \\
\text { preenchida por grãos de Cádmio. }\end{array}$ \\
\hline Fosfato $\left(\mathrm{PO}_{4}{ }^{3-}\right)$ & $\begin{array}{l}\text { Método colorimétrico. Formação } \\
\text { complexo reduzido de cor azul } \\
\text { após a reação do ortofosfato com } \\
\text { molibdto de amônia e tártaro de } \\
\text { antimônio. }\end{array}$ \\
\hline Silício (Si) & $\begin{array}{l}\text { Método Colorimétrico. } \\
\text { Determinado como ácido } \\
\text { ortosilícilico }\left(\mathrm{H}_{2} \mathrm{SiO}_{4}\right)\end{array}$ \\
\hline $\begin{array}{c}\text { Carbono } \\
\text { orgânico } \\
\text { Particulado }\end{array}$ & $\begin{array}{l}\text { Método Titulométrico. Os filtros } \\
\text { são digeridos com ácido sulfúrico } \\
\text { e dicromato de potássio e titulado } \\
\text { com uma solução de sulfato } \\
\text { ferroso amoniacal. }\end{array}$ \\
\hline $\begin{array}{c}\text { Material } \\
\text { Particulado em } \\
\text { Suspensão (SS) } \\
\end{array}$ & $\begin{array}{l}\text { Método Gravimétrico. } \\
\text { Determinado a partir dos filtros } \\
\text { com porosidade de } 0,45 \mu \mathrm{M}\end{array}$ \\
\hline $\begin{array}{c}\text { Demanda } \\
\text { Bioquímica de } \\
\text { oxigênio }\left(\mathrm{DBO}_{5}\right)\end{array}$ & $\begin{array}{l}\text { Amostras incubadas a } 20^{\circ} \mathrm{C} \text { por } 5 \\
\text { dias com leitura no inicio e no } \\
\text { final do oxigênio dissolvido. }\end{array}$ \\
\hline Clorofila-a (cla-a) & $\begin{array}{l}\text { Extração dos filtros com acetona } \\
90 \% \text { lidas no Fluorímetro Turner } \\
\text { Designs@ TD-700 }\end{array}$ \\
\hline $\begin{array}{l}\text { Coliformes } \\
\text { Fecais }\end{array}$ & Colilert \\
\hline
\end{tabular}

Referência: Strickland \& Parsons 1972; APHA-AWWA-WPCF, 1998

(Temperatura, Salinidade, $\mathrm{pH}$ e oxigênio dissolvido), com sondas multiparamétricas (Sonda Horiba U10/Sonda Multiparâmetros YSI 6600) em 8 estações amostrais (Figura 1).

Alíquotas de água foram coletadas na superfície das 8 estações amostrais. Nas estações \#6, \#7 e \#8 além da coleta na superfície foi realizado também uma coleta próximo ao fundo. Estas alíquotas foram levadas ao laboratório com a finalidade de se determinar as concentrações de nutrientes inorgânicos dissolvidos $\left(\mathrm{NH}_{4}^{+}, \mathrm{NO}_{2}, \mathrm{NO}_{3}^{-}, \mathrm{PO}_{4}^{3-}\right.$ e Si), Carbono orgânico particulado (COP), material particulado em suspensão (SS), Demanda Bioquímica de oxigênio $\left(\mathrm{DBO}_{5}\right)$, Clorofila-a (Cla-a) e Coliformes fecais. A metodologia para todos os parâmetros está descrita na Tabela 3.

Pela grande quantidade de dados utilizou-se métodos estatísticos multivariados para avaliar as relações das variáveis monitoradas. $\mathrm{Na}$ avaliação espacial foi aplicada uma técnica de agrupamento com a finalidade de formar grupos de trechos do rio com as mesmas características de qualidade de água. A análise de agrupamento foi feita a partir das 8 estações de monitoramento ao longo do estuário. A matriz de dados utilizada baseou-se na média padronizada de cada variável de qualidade de água em relação a toda série histórica. Nesta análise foi utilizada a distância Euclidiana como índice de dissimilaridade. A distância Euclidiana é um índice adequado quando são incluídas variáveis biológicas e ambientais para interpretação de dados ecológicos (CLARKE; WARWICK, 2001). O método de agrupamento usado foi o método de Ward ou método de agrupamento pela variância mínima.

Após o agrupamento, foram realizadas análises de variância (ANOVA), para testar se as variáveis que formaram cada trecho de rio, apresentam diferenças estatísticas significativas e com isso avaliar a eficiência de separação do agrupamento, com o nível de significância de 5\%.

Para avaliar o padrão de variação temporal aplicou-se uma análise de componentes principais (ACP) para cada trecho do estuário. Está análise tem como objetivo extrair as variáveis responsáveis pela maior variabilidade do conjunto de dados e mostrar a relação entre as variáveis de modo a facilitar a interpretação. (MUSTAPHA; ARIS, 2011). Essa relação é feita a partir de uma matriz de correlações entre as variáveis. Um conjunto de eixos perpendiculares que explicam uma parte da variância total dos dados serão formados e o comprimento desses eixos representa sua contribuição à variância total dos dados. A matriz de dados contém os dados das variáveis logaritimizados e foi retirada as variáveis que apresentaram mais que $20 \%$ de dados faltantes na série total.

Realizou-se também análise de correlação básica utilizando-se o coeficiente de correlação de Pearson com análise de variância a nível de $5 \%$ de probabilidade, entre os dados de descarga fluvial, SS e COP afim de avaliar se estas variáveis tiveram comportamento semelhante ao longo da série temporal.

Outra forma de analisar as variáveis em estudo é a comparação dos valores com a legislação pertinente, pois o resultado nos mostra como se encontra a qualidade da água do local. Conforme o artigo 42 da Resolução CONAMA 357/2005, os rios que não apresentam enquadramento conforme esta resolução se enquadram como rios de água doce classe 2 . As águas que apresentam salinidade superior a 0,5 são consideradas salobras e estas quando não possuem enquadramento deve seguir os padrões de água salobras classe 1 .

\section{RESULTADOS E DISCUSSÃO}

\section{Variação espacial}

A partir do proposto por Schettini (2002), o qual dividiu o estuário do rio Itajaí-Açu em 3 segmentos, optou-se por realizar uma análise de agrupamento sobre as 8 estações amostrais afim também de identificar segmentos do estuário que possuem características semelhantes em relação a qualidade de água. A resposta foi a formação de um dendrograma (Figura 2) com o agrupamento das estações de maior semelhança entre si em relação as variáveis analisadas.

Através do dendrograma (Figura 2) observa-se a sub- 


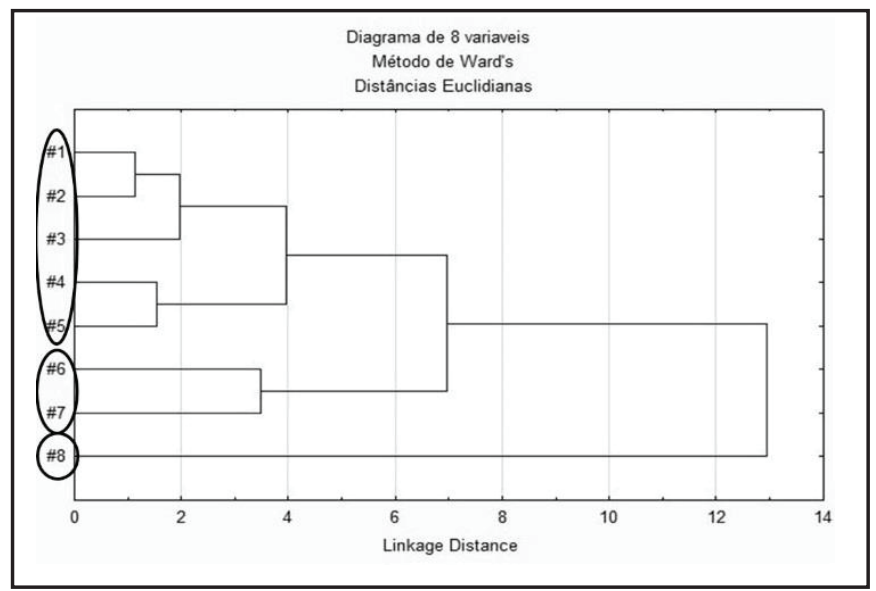

Figura 2 - Dendrograma formado a partir da matriz padronizado das variáveis em estudo ao longo do estuário

divisão do estuário também em três regiões: o alto estuário compreendendo as estações (\#1 a \#5) representando a parte fluvial do estuário entre os municípios de Blumenau e Ilhota; médio estuário (\#6 \#7) englobando os municípios de Ilhota e Itajaí; e o baixo estuário (\#8) sendo a porção final do estuário. A tabela 5 apresenta a média espacial dos valores das variáveis analisadas de toda a série histórica (2003-2011) por segmento de estuário.

Com a aplicação do teste de variância obteve-se como resposta o comportamento das variáveis ao longo do estuário (Tabela 5) se estas apresentaram semelhança ou não. Todas as variáveis apresentaram o valor de p menor que o erro estabelecido $(0,05)$ significando que nem todas as médias das variáveis são iguais entre os segmentos do estuário, sendo assim necessário um teste posterior. O teste posterior escolhido foi o teste de Fischer, pois os coeficientes de variação das amostras foram maiores que $10 \%$. As variáveis que apresentaram valores abaixo de 0,05 (Tabela 5) tiveram comportamento diferente entre os segmentos do estuário. As principais diferenças foram encontradas para as variáveis salinidade e $\mathrm{NO}_{3}^{-} \mathrm{OD}, \mathrm{pH}, \mathrm{DBO}_{5}, \mathrm{NH}_{4}^{+}, \mathrm{NO}_{2}^{-}$e $\mathrm{PO}_{4}^{3-}$.

Em relação aos parâmetros físico-químicos a salinidade apresentou diferença entre os segmentos do estuário. Todas as amostragens de salinidade no alto estuário foram 0 . No médio estuário a máxima chegou a 11 e foi aumentando em direção à boca do estuário chegando a 3 no baixo estuário. As amostras de fundo apresentaram maiores valores de salinidade em relação a superfície. Esta tendência é função da influência da intrusão da água marinha, de maior densidade, pois o estuário do rio Itajaí-Açu é classificado como tipo cunha salina.

A concentração média de oxigênio dissolvido no alto estuário foi de $7,8 \mathrm{mg} / 1 \mathrm{O}_{2}$, superior aos demais segmentos e decaindo em direção a boca do estuário, com valores médios em torno de $6 \mathrm{mg} / 1 \mathrm{O}$, no baixo estuário (Tabela 4). O decaimento do OD está relacionado com a entrada da carga poluidora rica em matéria orgânica ao longo do estuário que ao ser degradada resulta no consumo de oxigênio dissolvido. Outro fator a ser considerado é que no alto estuário há a presença de correntezas ocasionando a oxigenação da água, sendo estas ausentes na porção final do estuário.

As concentrações de OD no fundo foram menores do que em superfície (Tabela 4). Na camada superficial por estar em contato com a atmosfera ocorre a troca de gases entre os dois compartimentos ocasionando uma maior concentração na superfície. A entrada da cunha salina causa o isolamento da camada de fundo dificultando a troca de água entre as duas massas de água. A menor concentração de OD está relacionada também a maior concentração de matéria orgânica, visto que os valores de $\mathrm{DBO}_{5}$ também foram maiores na maioria dos casos no fundo (Tabela 4). Além disso a região do baixo estuário é constantemente dragada para a manutenção do canal de acesso à região portuária de Itajaí e Navegantes. A dragagem ocasiona ainda suspensão do material de fundo, favorecendo o consumo do oxigênio dissolvido presente na coluna da água.

$\mathrm{A} \mathrm{DBO}_{5}$ apresentou concentração média de $2,5 \mathrm{mg} / 1 \mathrm{no}$ alto estuário e diminui em direção a boca do estuário. Geralmente a $\mathrm{DBO}_{5}$ apresenta comportamento inverso do OD, portanto o esperado seria que esse segmento tivesse os menores valores de $\mathrm{DBO}_{5}$. Sugere-se que exista uma forte entrada de matéria orgânica, a qual pode ser proveniente dos municípios do alto

Tabela 4 - Valores de média, desvio padrão, máximo, mínimo das variaveis de qualidade da água por segmento do estuário

\begin{tabular}{|c|c|c|c|c|c|c|}
\hline Variável & & Méd & DV & Máx & Mín & $\mathbf{N}$ \\
\hline \multirow{3}{*}{ Salinidade } & Alto & 0 & 0 & 0 & 0 & 46 \\
\hline & Médio & 2 & 3 & 11 & 0 & 67 \\
\hline & Baixo & 6 & 5 & 30 & 0 & 68 \\
\hline \multirow{5}{*}{ OD mg/l } & Alto & 7,8 & 1,2 & 10,5 & 4,3 & 71 \\
\hline & Médio & 6,6 & 1,6 & 10,9 & 3,8 & 68 \\
\hline & Baixo & 6,3 & 1,7 & 12,9 & 2,7 & 69 \\
\hline & Médio F & 5,3 & 1,5 & 9,0 & 2,1 & 67 \\
\hline & Baixo F & 5,4 & 1,6 & 8,4 & 2,0 & 54 \\
\hline \multirow{5}{*}{$\mathbf{D B O}_{5} \mathrm{mg} / \mathrm{l}$} & Alto & 2,5 & 0,9 & 4,5 & 0,9 & 58 \\
\hline & Médio & 1,7 & 1,0 & 6,7 & 0,5 & 62 \\
\hline & Baixo & 1,5 & 1,2 & 7.6 & 0.0 & 64 \\
\hline & Médio F & 2,3 & 1,5 & 6,8 & 0,50 & 57 \\
\hline & Baixo F & 2,2 & 2,0 & 12,4 & 0,40 & 60 \\
\hline \multirow{3}{*}{ SS $\quad \mathrm{mg} / \mathrm{l}$} & Alto & 82,8 & 114 & 13 & 707 & 59 \\
\hline & Médio & 65,0 & 92,8 & 11,2 & 662 & 60 \\
\hline & Baixo & 49,9 & 78,3 & 4,4 & 486 & 59 \\
\hline \multirow{3}{*}{ COP $\mathrm{mg} / 1$} & Alto & 203 & 230 & 1172 & 20,5 & 57 \\
\hline & Médio & 160 & 156 & 996 & 19,1 & 55 \\
\hline & Baixo & 154 & 169 & 934 & 4,4 & 71 \\
\hline \multirow{3}{*}{$\mathbf{N H}_{4}{ }^{+} \quad \mu \mathrm{M}$} & Alto & 22,9 & 11,6 & 67,7 & 4,4 & 71 \\
\hline & Médio & 29,5 & 12,6 & 78,7 & 10,1 & 69 \\
\hline & Baixo & 31,7 & 11,2 & 60,2 & 12,6 & 67 \\
\hline \multirow{3}{*}{$\mathbf{N O}_{3}{ }^{-} \quad \mu \mathrm{M}$} & Alto & 49,3 & 14,2 & 89,6 & 10,9 & 62 \\
\hline & Médio & 38,4 & 13,6 & 77,9 & 9,8 & 63 \\
\hline & Baixo & 29,6 & 14,1 & 74,8 & 1,9 & 60 \\
\hline \multirow{3}{*}{$\mathbf{P O}_{4}^{3-} \quad \mu \mathrm{M}$} & Alto & 1,5 & 0,7 & 4,7 & 0,3 & 71 \\
\hline & Médio & 1,1 & 0,6 & 4,0 & 0,3 & 71 \\
\hline & Baixo & 1,1 & 0,8 & 6,0 & 0,0 & 68 \\
\hline \multirow{3}{*}{$\mathbf{S}_{\mathrm{i}} \quad \mu \mathrm{M}$} & Alto & 77,5 & 57,6 & 408 & 3,7 & 83 \\
\hline & Médio & 86,0 & 52,0 & 238 & 9,1 & 81 \\
\hline & Baixo & 87,0 & 52,6 & 274 & 3,4 & 67 \\
\hline
\end{tabular}


Tabela 5 - Resultado da ANOVA em relação ao segmento do estuário com as variáveis com um nível de significância de 5\% e FISHER como teste posterior

\begin{tabular}{|c|c|c|c|c|}
\hline \multirow[t]{2}{*}{ Variável } & \multicolumn{4}{|c|}{ Estuário } \\
\hline & & Alto & Médio & Baixo \\
\hline \multirow[t]{3}{*}{ Salinidade } & Alto & & 0,00 & 0,00 \\
\hline & Médio & 0,00 & & 0,00 \\
\hline & Baixo & 0,00 & 0,00 & \\
\hline \multirow[t]{3}{*}{ OD } & Alto & & 0,00 & 0,00 \\
\hline & Médio & 0,00 & & 0,27 \\
\hline & Baixo & 0,00 & 0,27 & \\
\hline \multirow[t]{3}{*}{$\mathrm{pH}$} & Alto & & 0,00 & 0,00 \\
\hline & Médio & 0,00 & & 0,20 \\
\hline & Baixo & 0,00 & 0,20 & \\
\hline \multirow[t]{3}{*}{ SS } & Alto & & 0,32 & 0,06 \\
\hline & Médio & 0,32 & & 0,38 \\
\hline & Baixo & 0,06 & 0,38 & \\
\hline \multirow[t]{3}{*}{ Cla-a } & Alto & & 0,87 & 0,83 \\
\hline & Médio & 0,87 & & 0,96 \\
\hline & Baixo & 0,83 & 0,96 & \\
\hline \multirow[t]{3}{*}{$\mathrm{DBO}_{5}$} & Alto & & 0,00 & 0,00 \\
\hline & Médio & 0,00 & & 0,47 \\
\hline & Baixo & 0,00 & 0,47 & \\
\hline \multirow{3}{*}{$\begin{array}{l}\text { Col. } \\
\text { Fecais }\end{array}$} & Alto & & 0,21 & 0,37 \\
\hline & Médio & 0,21 & & 0,72 \\
\hline & Baixo & 0,37 & 0,72 & \\
\hline \multirow[t]{3}{*}{ COP } & Alto & & 0,22 & 0,16 \\
\hline & Médio & 0,22 & & 0,86 \\
\hline & Baixo & 0,16 & 0,86 & \\
\hline \multirow[t]{3}{*}{$\mathrm{NH}_{4}{ }^{+}$} & Alto & & 0,00 & 0,00 \\
\hline & Médio & 0,00 & & 0,28 \\
\hline & Baixo & 0,00 & 0,28 & \\
\hline \multirow[t]{3}{*}{$\mathrm{NO}_{2}^{-}$} & Alto & & 0,07 & 0,17 \\
\hline & Médio & 0,07 & & 0,92 \\
\hline & Baixo & 0,17 & 0,92 & \\
\hline \multirow[t]{3}{*}{$\mathrm{NO}_{3}^{-}$} & Alto & & 0,00 & 0,00 \\
\hline & Médio & 0,00 & & 0,00 \\
\hline & Baixo & 0,00 & 0,00 & \\
\hline \multirow[t]{3}{*}{$\mathrm{PO}_{4}{ }^{3-}$} & Alto & & 0,00 & 0,00 \\
\hline & Médio & 0,00 & & 0,83 \\
\hline & Baixo & 0,00 & 0,83 & \\
\hline \multirow[t]{3}{*}{ Si } & Alto & & 0,47 & 0,43 \\
\hline & Médio & 0,47 & & 0,95 \\
\hline & Baixo & 0,43 & 0,95 & \\
\hline
\end{tabular}

estuário que juntos possuem mais de 430 mil habitantes (Tabela 1) e não apresentam coleta e sistema de tratamento de efluentes, logo, provavelmente este material está sendo degradado ao longo do sistema. Na proximidade da boca do estuário ocorre a entrada de água marinha com menor quantidade de matéria orgânica ocasionando a diluição neste segmento sendo outro motivo e pode estar refletindo nas menores concentrações de $\mathrm{DBO}_{5}$ neste local.

Além da $\mathrm{DBO}_{5}$, maiores valores de Col. Fecais também foram encontrados no alto estuário corroborando com a hipótese que o município de Blumenau contribui com a entrada de efluentes domésticos no estuário. Rörig (2005) destaca que, o principal indicador de contaminação por esgoto doméstico, os coliformes fecais, apresentam contagens excessivas no Rio Itajaí-Açu nas áreas com maior percentual de urbanização, incluindo os municípios de Blumenau, Gaspar e Itajaí. O SS variou de $4 \mathrm{mg} / \mathrm{l}$ a $700 \mathrm{mg} / 1$ durante o tempo em estudo. Apesar desta alta variabilidade observa-se uma tendência de ocorrência dos maiores valores no alto estuário (Tabela 4), que pode estar relacionado com a presença de áreas agrícolas as margens do sistema estuarino. Estas causariam o aumento de SS no corpo hídrico, pois as culturas substituem a presença da mata ciliar. Vanzela et al., (2009) indicou como origem do aumento da concentração de sólidos no córrego Três Barras - Marinópolis a urbanização, agricultura e a mata degradada situações análogas encontradas na Bacia do rio Itajaí.

Assim como o SS o COP também apresentou o desvio padrão maior que a média com a mesma tendência de maiores valores no alto estuário como era esperado, pois o COP faz partedo SS. As maiores concentrações de SS e o COP foram encontradas no fundo, podendo estar relacionadas aos efeitos das correntes de maré no estuário, promovendo a ressuspensão do material sedimentado, assim aumentando as concentrações no fundo (PEREIRA FILHO et al., 2002). A Cla-a não apresentou uma variação espacial clara com média de 1,1 $\mu \mathrm{g} / 1$ nos três segmentos do estuário. $\mathrm{O}$ fundo mostrou valores superiores em relação á superfície em torno de $1,5 \mu \mathrm{g} / \mathrm{l}$ e 1,9 $\mu \mathrm{g} / \mathrm{l}$ para o médio e baixo estuário respectivamente. Isso sugere que ela é formada na região costeira e entra no estuário junto com a água marinha pelo fundo, já que o estuário é estratificado.

Entre os nutrientes inorgânicos dissolvidos o nitrato foi a forma que apresentou maior proporção enquanto o nitrito foi a forma menos abundante, o nitrato é um nutriente geralmente relacionado ao escoamento superficial de áreas agrícolas. As concentrações de nitrato mostraram diferenças ao longo do estuário (Tabela 4) decrescendo em direção á boca. As maiores concentrações no alto estuários estão relacionadas ao uso de fertilizantes a base de ureia nesta região. Sua oxidação no solo acarreta a entrada nitrato no corpo hídrico. Fluxos de NID estão relacionados com o uso agrícola na bacia. Altos valores de nitrato encontrados em um pequeno estuário chinês estiveram relacionados ao uso de fertilizantes e foi concluído que os usos destes contribuiu com até $67 \%$ do nitrogênio presente na água (KAISER et. al., 2013).

Ao contrário do nitrato, o nitrito e o nitrogênio amoniacal atingiram suas maiores concentrações no médio e baixo estuário. Para o amônio no alto estuário a média foi de $23 \mu \mathrm{M}$ enquanto no baixo estuário foi de $31 \mu \mathrm{M}$ (Tabela 4). Estando o nitrogênio amoniacal relacionado á entrada recente de matéria orgânica no ambiente, a presença de indústrias pesqueiras nas margens do estuário consequentemente tem participação no aumento do nitrogênio amoniacal, em função do lançamento de efluentes rico em orgânicos diretamente no estuário. Restos de matéria orgânica quando lançados no corpo hídrico se mineralizam liberando nitrogênio amoniacal para o meio. Além das indústrias pesqueiras no baixo estuário encontram-se dois grandes importantes centros urbanos da região os municípios de Itajaí e Navegantes, os quais também não apresentam coleta e tratamento de efluentes acarretando o lançamento de efluen- 
tes no corpo hídrico. As elevadas concentrações de nitrogênio amoniacal encontradas por Signorin et al. (2010) no estuário do rio Perequê evidenciaram que as ocupações das margens contribuem para a contaminação do ambiente através dos efluentes domésticos. A produção de efluentes domésticos e industriais, pode gerar cargas de nutrientes maiores do que a capacidade dos micro-organismos presentes no meio aquático tem de incorporar e mineralizar estes nutrientes (ABREU et al., 2010). Pereira Filho et al. (2006) estimaram que a entrada de efluente doméstico no baixo estuário do Rio Itajaí contribui com até $30 \%$ das entradas de nitrogênio amoniacal no estuário, em períodos de baixa descarga fluvial, reforçando a importância dos municípios de Itajaí e Navegantes para o sistema.

O fosfato mostrou comportamento semelhante ao do nitrato com as maiores concentrações no alto estuário, estando também relacionadas com o uso de fertilizantes. A média no alto estuário foi de $1,5 \mu \mathrm{M}$ enquanto que no médio e baixo estuário foi de $1,1 \mu \mathrm{M}$ (Tabela 4). Porém além dos fertilizantes o fosfato pode ter sua entrada a partir de efluentes domésticos, existem muitos detergentes que possuem em sua composição os polisfosfatos, e os detergentes estão presentes em grande quantidade nos efluentes domésticos. As concentrações relativamente baixas de fosfato no médio e baixo estuário podem estar associadas à sua tendência de se adsorver ao material particulado em suspensão em regiões estuarinas a partir da mistura da água doce e salgada. Essa hipótese é reforçada pela grande quantidade de SS presente na região. Em estuários chineses as baixas concentrações de fosfato encontradas foram relacionadas principalmente a este fenômeno de adsorção ao material particulado em suspensão (KAISER et al., 2013).

O silício foi o nutriente que apresentou as maiores concentrações entre os nutrientes inorgânicos dissolvidos com média de 77,5, 86,0 e 86,9 $\mu \mathrm{M}$ para o alto, médio e baixo estuário respectivamente. Esse nutriente é o único que não está associado a matéria orgânica, e pode estar relacionado com o intemperismo das rochas. Portanto a crescente urbanização e falta de mata ciliar pode ocasionar o aumento deste nutriente. $\mathrm{Na}$ bacia do Gama - DF as altas concentrações de Si foram relacionadas principalmente com a falta de vegetação, atividades da construção civil e expansão urbana (MOURA et al., 2010).

\section{Variação temporal}

Através dos dados de descarga fluvial do período em estudo (Figura 3) tem-se claramente definidos dois períodos com comportamento distintos: um onde a descarga fluvial foi mais baixa (2003-2009) com média $236 \mathrm{~m}^{3} / \mathrm{s}$ e o período de maior descarga fluvial (2010 e 2011) com média de $453 \mathrm{~m}^{3} / \mathrm{s}$.

A temperatura, como o esperado apresentou um claro padrão sazonal com as maiores temperaturas no verão e as menores no inverno, com a mínima chegando a $15^{\circ} \mathrm{C}$ e máxima em torno de $30^{\circ} \mathrm{C}$ (Figura 4).

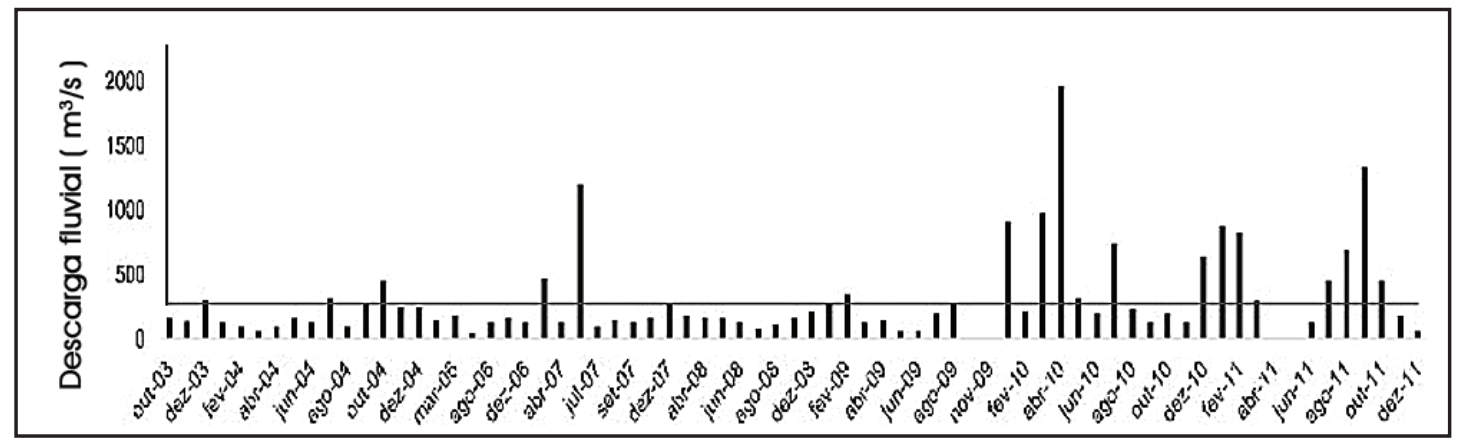

Figura 3 - Descarga fluvial 2003-2011- Média de 3 dias da descarga fluvial na estação fluviométrica de Indaial com a indicação da média histórica

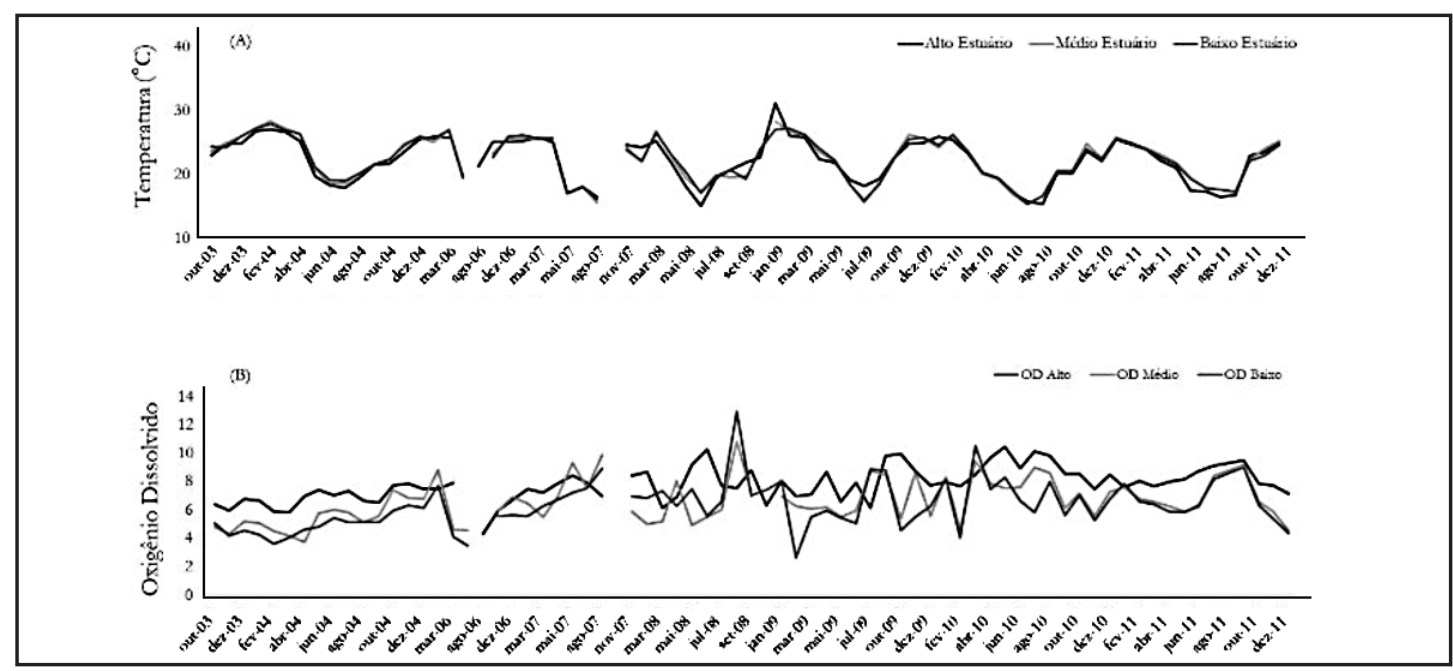

Figura 4 - Variação temporal da temperatura e do oxigênio dissolvido para os três segmentos do estuário 


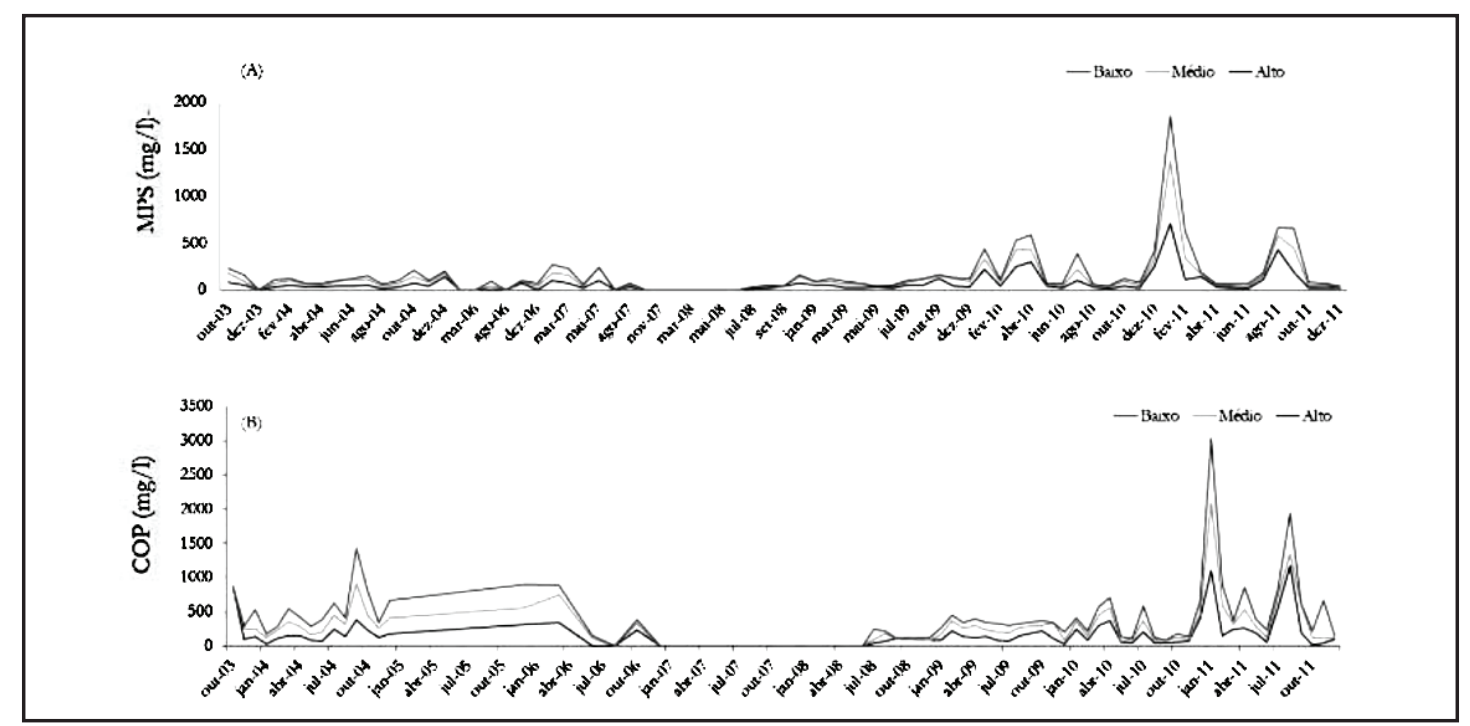

Figura 5 - Valores de sólidos suspensos (A) carbono orgânico particulado (B) para a série de dados (2003-2011)

O OD mostrou uma alta variabilidade temporal durante o período em estudo, porém observou-se uma pequena tendência de ocorrência de maiores valores no inverno e menores no verão (Figura 4), isto porque em altas temperaturas a solubilidade do oxigênio dissolvido diminui. No estuário de Cananéia em São Paulo esta tendência também foi observada, no entanto os valores no verão neste estuário foram na maioria dos casos abaixo de $4 \mathrm{mg} / 1$ (AZEVEDO; BRAGA, 2011) e no estuário do rio Itajaí-Açu este valor foi encontrado apenas em casos isolados na série inteira dos dados.

A alta variabilidade apresentada pelos dados de SS (Figura 5) sugere que além da agricultura exista outras variáveis influentes. Em trabalhos realizados no estuário do Itajaí-Açu e outros estuários brasileiros a presença de SS sempre mostrou forte relação com a descarga fluvial, com as maiores concentrações em períodos de alta descarga (BELLOTTO et al., 2009; PEREIRA FILHO et al., 2010; AZEVEDO; BRAGA, 2011).
Temporalmente os valores de SS apresentaram a distinção de dois períodos: baixas concentrações nos anos de 2003 a 2009 e altas concentrações em 2010 e 2011 (Figura 5) coincidindo com os períodos de baixa e alta descarga fluvial (Figura 3).A correlação entre estas duas variáveis foi positiva $(\mathrm{r}=0,75)$ mostrando comportamento similar. Os altos valores observados em agosto e setembro de 2011 (431 e $191 \mathrm{mg} / \mathrm{l}$ ) podem estar associados, além do fato das altas descargas neste período, à exposição do solo que ocorre nestes meses devido ao preparo do solo para o cultivo de arroz, ocasionando o carreamento do SS para o corpo hídrico (SILVA; PEREIRA FILHO, 2010).

Temporalmente o COP mostrou também a distinção de dois períodos, com as menores concentrações no período de baixa descarga fluvial e as maiores concentrações no período de alta descarga fluvial, como uma correlação positiva $(\mathrm{r}=0,72)$, coincidindo com a tendência encontrada para o SS (Figura 5).

O nitrito e o nitrogênio amoniacal apresentaram alguns

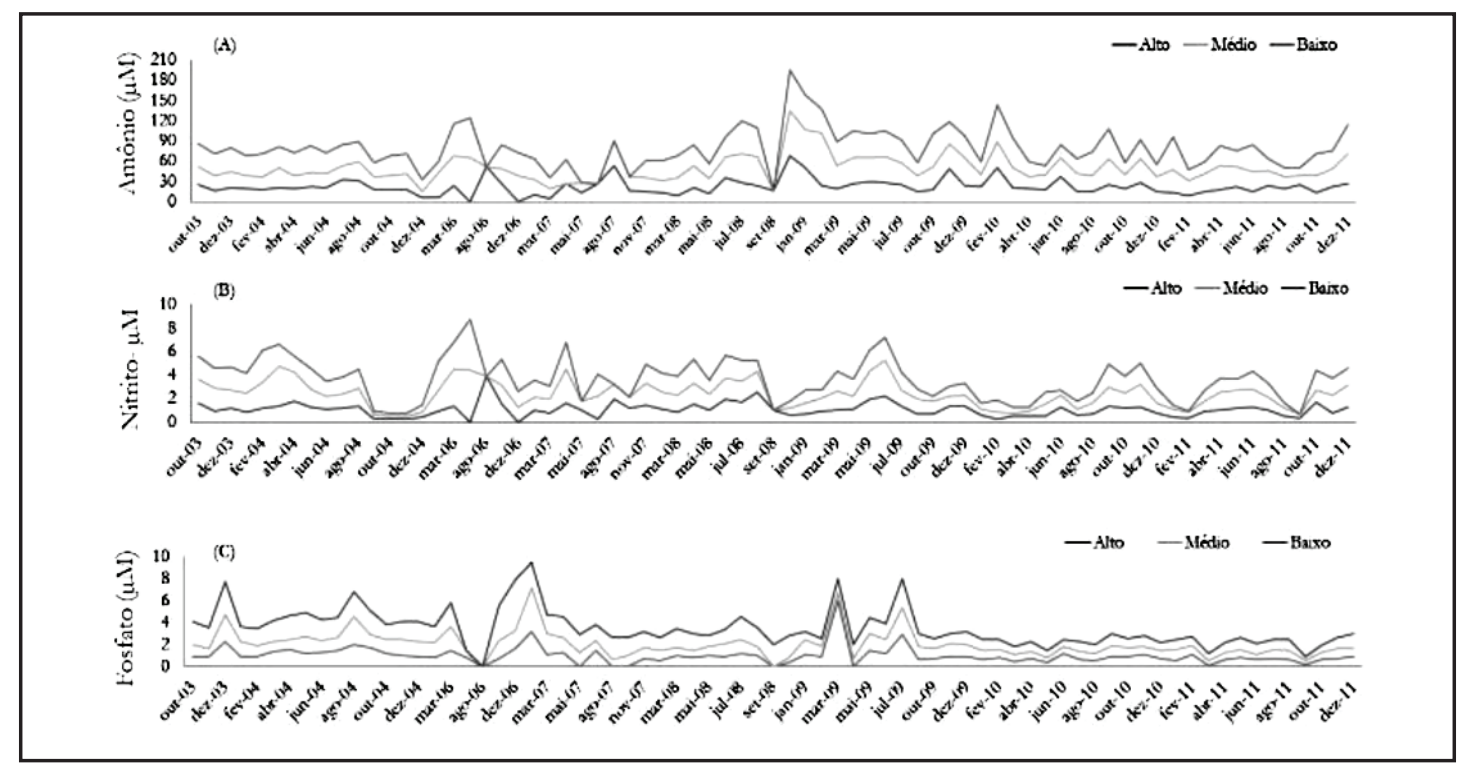

Figura 6 - Valores de nitrogênio amoniacal (A) e Nitrito (B) e Fosfato (C) de toda a série (2003-2011) ao longo do estuário 
Tabela 6 - Autovalores da análise de componentes principais realizada sobre os dados logaritimizados de toda a série temporal em estudo para o alto médio e baixo estuário (2003-2013)

\begin{tabular}{l|c|c|l|c|l|l|c|c}
\hline \multicolumn{3}{c|}{ Alto estuário } & \multicolumn{3}{c|}{ Médio estuário } & \multicolumn{3}{c}{ Baixo estuário } \\
\hline & Eixo 1 & Eixo 2 & Eixo1 & \multicolumn{2}{|c|}{ Eixo2 } & Eixo1 & Eixo2 \\
\hline Vazão & $\mathbf{0 , 9 3}$ & 0,03 & SS & $\mathbf{0 , 8 6}$ & $-0,27$ & Vazão & $\mathbf{0 , 9 1}$ & $-0,10$ \\
\hline SS & $\mathbf{0 , 8 2}$ & 0,41 & Vazão & $\mathbf{0 , 7 9}$ & 0,11 & SS & $\mathbf{0 , 8 0}$ & 0,19 \\
\hline OD & $\mathbf{0 , 6 5}$ & $-0,59$ & OD & $\mathbf{0 , 6 7}$ & 0,44 & OD & $\mathbf{0 , 6 3}$ & $-0,34$ \\
\hline NO3 & 0,15 & $-0,33$ & Cla-a & 0,35 & $-0,38$ & NO3 & 0,35 & 0,50 \\
\hline Cla-a & 0,05 & 0,53 & NO3 & 0,31 & 0,41 & Cla-a & $-0,08$ & $\mathbf{0 , 8 0}$ \\
\hline Temp & $-0,19$ & $\mathbf{0 , 7 4}$ & DBO & 0,08 & 0,36 & Temp & $-0,10$ & 0,18 \\
\hline NH4 & $-0,27$ & $-0,45$ & Temp & $-0,15$ & $-0,78$ & PO4 & $-0,18$ & $\mathbf{0 , 7 0}$ \\
\hline Si & $-0,56$ & $-0,37$ & $\mathbf{P O 4}$ & $-0,38$ & $-0,58$ & DBO & $-0,20$ & 0,37 \\
\hline PO4 & $-\mathbf{0 , 6 4}$ & 0,43 & Si & $-0,49$ & 0,36 & pH & $-0,20$ & $-0,48$ \\
\hline pH & $-\mathbf{0 , 6 5}$ & $-0,03$ & NH4 & $-0,52$ & 0,02 & Si & $-0,59$ & $-0,10$ \\
\hline NO2 & $\mathbf{- 0 , 6 8}$ & $-0,17$ & pH & $-0,56$ & 0,31 & NH4 & $\mathbf{- 0 , 6 5}$ & $-0,11$ \\
\hline & & & NO2 & $\mathbf{- 0 , 8 0}$ & 0,01 & Sal & $-\mathbf{0 , 8 4}$ & 0,07 \\
\hline & & & Sal & $\mathbf{- 0 , 8 9}$ & 0,16 & NO2 & $\mathbf{- 0 , 8 6}$ & $-0,11$ \\
\hline
\end{tabular}

picos isolados durante a série de dados e uma pequena tendência de menores valores no final da série, o qual indica que estes nutrientes não estejam relacionados apenas com a descarga fluvial, que além da contribuição fluvial ocorre processos para sua produção no ambiente estuarino, como entrada antrópica pontual, decomposição da matéria orgânica ou processo de nitrificação como já observado por Bellotto et al.,(2009) neste estuário.

Temporalmente as concentrações de fosfato tenderam a diminuir a partir de 2009 em relação aos dados anteriores, não ocorrendo picos de altas concentrações em nenhum dos três segmentos (Figura 6), se igualando ao comportamento do nitrogênio amoniacal e do nitrito. Verificou-se também que as concentrações diminuíram praticamente pela metade no final da série quando comparado com início, sendo justificadas pelo aumento do SS observado nesta época que pode ter ocasionado a adsorção do fosfato ao material. Assim como para o nitrogênio amoniacal o fosfato pode não ter sua principal entrada a partir da descarga fluvial tendo outras fontes de entradas pontuais no próprio estuário. $\mathrm{Na}$ bacia hidrográfica do rio Yangtze, situada na costa da China, nos anos de seca, onde a descarga diminuiu significativamente ocorreu um aumento na concentração de nutrientes em comparação com os valores médios (CHEN et al., 2012).

A tabela 6 mostra as variáveis de maior destaque em cada segmento do estuário através dos autovalores. Os autovalores correspondem aos pesos de cada variável e são usados para interpretar os eixos (fator). As variáveis mais importantes são as de maior peso positivo ou negativo o sinal do peso indica se é correlação positiva ou negativa.

Para o alto estuário o eixo 1 (Tabela 6) foi formado pelos altos valores positivos das variáveis SS, descarga fluvial e OD. No inverso apareceu a variável $\mathrm{pH}$, nitrito e fosfato. Este primeiro eixo ilustra que a entrada de SS foi fortemente associada com a descarga fluvial, que com o aumento das chuvas ocorre o carreamento do solo para o corpo hídrico. O OD ter se relacionado positivamente com a descarga fluvial sugere que o aumento da descarga causou o aumento a turbulência da água ocasionando maior oxigenação. Os autovalores negativos de $\mathrm{NO}_{2}$ - e do $\mathrm{PO}_{4}^{3-}$ neste eixo indicam uma correlação inversa com a descarga fluvial confirmando que há outros fatores que influenciaram nestas variáveis e em baixas descargas a concentração destes nutrientes aumentou.

A não relação do silício com a descarga fluvial no plano formado indica que este nutriente pode estar sendo influenciado por outros fatores, por exemplo o ciclo de arroz. A planta de arroz é composta de 30\% do seu peso de silício e dentre os nutrientes o silício é assimilado pelas raízes da planta rapidamente sendo a planta, portanto reconhecida como um acumulador de silício (SILVA; PEREIRA FILHO, 2010 apud TAKAHASHI, 1995). O eixo 2 foi formado apenas pela temperatura no lado positivo e no lado negativo o OD, mostrando que o OD teve maiores dificuldade em se solubilizar em águas mais quentes.

No médio estuário o eixo 1 (Tabela 6) continuou sendo representado pela descarga fluvial, SS e OD em sua extremidade positiva. Por outro lado, além do nitrito a salinidade também foi destaque na extremidade negativa mostrando correlação inversa com a descarga fluvial. Em alta descarga fluvial a água marinha é diluída e expulsa do estuário diminuindo os valores de salinidade.Em períodos de baixa descarga a água marinha exerce maior influência no estuário. O eixo 2 foi semelhante ao alto estuário com a temperatura e o OD presentes na extremidade negativa e positiva respectivamente.

Para o baixo estuário temos o eixo 1 também representado positivamente pelas variáveis OD, SS e descarga fluvial (Tabela 6). Ao comparar a água marinha com a fluvial verifica-se que a água doce possui maior capacidade de solubilizar o OD, sendo uma justificativa para a correlação positiva formada. $\mathrm{Na}$ parte negativa além da salinidade ainda se encontram as variáveis nitrito e nitrogênio amoniacal. Mesmo em baixa descarga fluvial existe a entrada de nitrogenados no estuário principalmente a partir das indústrias pesqueira instaladas nas margens do estuário, além dos efluentes domésticos.

$\mathrm{Na}$ análise temporal e com a ajuda da análise multivariada nota-se que evolução das variáveis é mascarada devido à forte influência da descarga fluvial neste estuário. A concentração 
da maioria das variáveis (e.gSS, fosfato, nitrito, amônio) foram explicadas conforme a variação da descarga fluvial no período. Nota-se também a dificuldade de observar, descrever e relacionar as tendências que estas variáveis sofrem principalmente os nutrientes inorgânicos dissolvidos, ao longo de um período. Isto porque a água do estuário é renovada periodicamente sob a influência da maré (MIRANDA et al., 2002).

Schaffelke et al. (2011) no monitoramento de longo período realizado em uma lagoa costeira de barreira de recifes retirou os dados de nutrientes dissolvidos da análise, pois as concentrações eram variáveis em uma curta escala de tempo e espaço não sendo possível verificar os padrões temporais e espaciais. Eldson et al. (2009) sugere a necessidade de avaliar os impactos do uso e ocupação do solo juntamente com um contexto natural devido a variação das concentrações de nutrientes ocorrer em uma curta escala de tempo.

Na região estuarina da lagoa dos Patos, durante as últimas duas décadas as concentrações dos nutrientes inorgânicos dissolvidos mostraram distintos comportamentos, com ausência de correlação com a chuva, seston, temperatura, salinidade, sendo justificada esta ausência de correlação com os processos que ocorrem no sedimento ou com a intensa hidrodinâmica que acontece no ambiente, requerendo amostragens de NID em curta escala de tempo como também a medição de outras variáveis como vento, evapotranspiração e precipitação que podem ter grande influência sobre as variáveis (ABREU et al., 2010).

\section{Comparação com a legislação}

Apartir das variáveis que constam na resolução 357/2005 realizou-se uma tabela com o resultado da porcentagem de inconformidade das variáveis em relação aos limites estabelecidos (Tabela 7).

No alto estuário nota-se que apenas o pH e os Col. Fecais apresentaram valores fora dos padrões estabelecidos. $\mathrm{O}$ $\mathrm{pH}$ apresentou apenas um valor fora do padrão. Os Coliformes Fecais já apresentaram $80 \%$ dos valores fora dos estabelecido pela legislação. $\mathrm{O}$ restante das variáveis obtiveram valores afastados dos limites (Tabela 7). O médio e baixo estuário já tiveram a maioria dos seus dados fora dos padrões estabelecidos pelo CONAMA e portanto realizou-se uma análise mais especifica comparando as inconformidades entre períodos de alta e a baixa descarga fluvial.

A baixa descarga refere-se aos meses dos anos de 2003 até 2009 e a alta descarga refere-se aos meses dos anos de 2010 e 2011. A porcentagem de cada período é apresentada na Tabela 8 . No médio estuário o oxigênio dissolvido mostrou 3 dos 68 dados abaixo de $5 \mathrm{mg} / 1$ (4\%) todos registrados no período de baixa descarga. O baixo estuário apresentou 9 dos 69 dados (13\%) fora do padrão estabelecido, ocorridos também no período de baixa descarga. Em relação aos nitrogenados inorgânicos dissolvidos, apenas o $\mathrm{NO}_{2}^{-}$não apresentou valores em desacordo com a legislação. $\mathrm{O} \mathrm{NH}_{4}^{+}$apresentou $40 \%$ e 65 $\%$ dos seus dados fora dos limites da legislação para o médio e baixo estuário respectivamente. No médio estuário as porcentagens não apresentaram grande diferença entres os períodos de baixa e alta descarga, ao contrário da região do baixo estuário.
Tabela 7 - Porcentagem de inconformidade das variáveis que constam na resolução CONAMA 357/05

\begin{tabular}{c|c|c|c}
\hline & $\begin{array}{c}\text { Alto } \\
\text { estuário }\end{array}$ & $\begin{array}{c}\text { Médio } \\
\text { estuário }\end{array}$ & $\begin{array}{c}\text { Baixo } \\
\text { estuário }\end{array}$ \\
\hline OD (\%) & 0 & 4 & 13 \\
\hline pH (\%) & 2 & 9 & 6 \\
\hline Col. Fecais (\%) & 80 & 85 & 93 \\
\hline $\mathbf{N O}_{2}^{-}(\mathbf{0})$ & 0 & 0 & 0 \\
\hline $\mathbf{N O}_{3}-\mathbf{( \% )}$ & 0 & 75 & 58 \\
\hline $\mathbf{N H}_{\mathbf{4}} \mathbf{(}^{(\mathbf{*} \%)}$ & 0 & 40 & 65 \\
\hline
\end{tabular}

Tabela 8 - Porcentagem de inconformidade das variáveis que constam na resolução CONAMA 357/05 em relação alta e baixa descarga fluvial

\begin{tabular}{c|c|c|c|c}
\hline & \multicolumn{2}{|c|}{ Médio estuário } & \multicolumn{2}{c}{ Baixo estuário } \\
\hline Variável & Alta & Baixa & Alta & Baixa \\
\hline OD (\%) & 0 & 9 & 7 & 15 \\
\hline pH (\%) & 8 & 9 & 4 & 7 \\
\hline $\mathbf{N H}_{4}^{+} \mathbf{( \% )}$ & 37 & 45 & 37 & 81 \\
\hline $\mathbf{N O}_{3}^{-}(\mathbf{\%})$ & 87 & 64 & 58 & 58 \\
\hline Col Fecais (\%) & 79 & 84 & 83 & 94 \\
\hline
\end{tabular}

Para o nitrato mais de $50 \%$ dos valores no médio e baixo estuário ficaram acima do exigido pela legislação. Ao contrário do nitrogênio amoniacal o nitrato apresentou maior diferença entre os períodos no médio estuário, já no baixo estuário a porcentagem foi semelhante nos dois períodos. Os Col. Fecais apresentaram 85\% e 93\% para o médio e baixo estuário respectivamente acima dos padrões estabelecidos pela legislação.

Em comparação entre segmentos do estuário nota-se que o alto estuário possui melhor qualidade de água em relação ao médio e baixo estuário. No médio e baixo estuário já se verifica a degradação da qualidade de água devido a maioria das variáveis apresentarem valores fora dos padrões estabelecidos pelo CONAMA principalmente nos períodos de baixa descarga fluvial. Os valores das concentrações não se diferenciaram muito entre os segmentos, esta diferença no momento de comparar com a legislação é devido aos limites estabelecidos para águas salobras serem muito mais rígidas do que para aguas doces, pois estes ambientes são locais onde ocorre misturas de massas da água e consequentemente diluição dos nutrientes.

No estuário Santos São Vicente-SP as variáveis OD, fosfato, nitrato, nitrito e nitrogênio amoniacal ficaram fora dos padrões estabelecidos pela legislação, principalmente nos dados medidos no verão (AZEVEDO; BRAGA, 2011). Esta tendência foi observada no presente estudo com os valores de OD, que estiveram em inconformidade principalmente nos meses do verão. Na bacia hidrográfica do rio Zhangweinan na China, um estudo da qualidade da água realizado em um período de 7 anos mostrou que os anos iniciais tiveram uma classificação da água fora dos padrões exigidos, porém os anos finais de análise a qualidade da água mostrou uma grande melhora nos resultados, fato corrobado principalmente pela gestão cientifica ou da aplicação rigorosa que vinha acontecendo nos últimos anos (XU et al., 2012) 


\section{CONCLUSÕES}

A avaliação espacial mostrou que as variáveis de qualidade de água possuem comportamento diferenciado ao longo do estuário. O OD, SS, COP, $\mathrm{DBO}_{5}$, Col. Fecais e nitrato, apresentaram maiores valores no alto estuário sugerindo que estejam associadas a dinâmica do local, a maior população e maior área agrícola. A salinidade, $\mathrm{pH}$, nitrito e nitrogênio amoniacal mostraram maiores valores no médio e baixo estuário sendo este segmento influenciado pela entrada da água marinha. As maiores concentrações de nitrogênio amoniacal no baixo estuário sugerem influência do efluente doméstico dos municípios de Itajaí e Navegantes, além dos provenientes da indústria pesqueira.

$\mathrm{Na}$ variabilidade temporal, identificou-se a descarga fluvial como o fator de maior influência no comportamento das variáveis de qualidade de água. O SS, COP, col. Fecais, nitrato e silício apresentaram maiores concentrações em períodos de alta descarga fluvial enquanto a salinidade, nitrito e a nitrogênio amoniacal apresentaram menores concentrações em alta descarga fluvial.

A descarga fluvial foi mais importante para explicar as tendências que ocorreram com as variáveis da qualidade de água, dificultando a avaliação da evolução das mesmas em relação a mudança do uso do solo e urbanização.

Conforme os padrões estabelecidos pela resolução do Conama 357/05 o alto estuário apresentou maiores conformidades com a legislação. Porém o médio e baixo estuário apresentaram a maioria das suas variáveis em inconformidade sendo um indicio que as atividades desenvolvidas na bacia têm efeito na porção final da bacia.

As medidas de coleta e tratamento de efluentes, que serão implantadas na região são uma forma de melhorar os valores das variáveis relacionadas a entrada de matéria orgânica, visto que o médio e o baixo estuário já se encontram com a maioria dos valores das variáveis fora dos padrões estabelecidos pela legislação, principalmente a variável coliforme fecal. A falta de mata ciliar nas margens do estuário seria outra questão de ser abordada, pois a falta dela ocasiona a maior entrada de SS e de outros materiais proveniente das atividades antrópicas.

\section{AGRADECIMENTOS}

Todas as pessoas envolvidas nas diversas campanhas de campo e processamento das análises;

A Pro-Reitoria de Pesquisa, Pós-Graduação, Extensão e Cultura da UNIVALI, pelo incentivo a pesquisa através de uma bolsa de IC (PROBIC) e recursos financeiros.;

A FAPESC, pelo apoio financeiro (edital 05/2009; termo de outorga 171888/2009-3.

\section{REFERÊNCIAS}

ABREU, P. C.; ODEBRECHT, C.; NIENCHESKI, L.F. Nutrientes Dissolvidos. In: SEELINGER, C.; ODEBRECHT,C. (Orgs). O estuário da lagoa dos Patos: um século de transformações. Rio
Grande do Sul: FURG, Cap. 4, 2010. p. 43-51.

AZEVEDO, J. S.; BRAGA, E. S. Caracterização hidroquímica para qualificação ambientais dos estuários de Santos-São Vicente e Cananéia. Arq. Ciên. Mar, v. 44, n. 2, p. 52-61, 2011.

APHA-AWWA-WPCF. Standard Methods for the Examination of Water and Wastewater. 17th Ed. Washington, DC: American Public and Health Association, American Water Works Association and Water Pollution Control Federation, 1998.

BELLOT'TO, V. R.; KUROSHIMA, K. N.; CECANHO, F. Poluentes no ambiente estuarino e efeitos da atividade de dragagem. In: BRANCO, J. O.; BRANCO, M.J.M.; BELLOTTO, V.R. (Orgs). Estuário do Rio Itajaí-Açu, Santa Catarina: caracterização ambiental e alterações antrópicas. Itajaí: UNIVALI, Cap. 7, 2009. p. 105-126.

CHEN,Y.; LIU, R.; SUN, C.; ZHANG, P.;FENG, C.; SHENZ. Spatial and temporal variations in nitrogen and phosphorous nutrients in the Yangtze river estuary. Marine Pollution Bulletin, v .64, p. 2083-2089, 2012.

CLARKE, K. R.; WARWICK, R. M. Change in marine communities: an approach to statistical analysis and interpretation. $2 \mathrm{ed}$. PRIMER-E Ltd. Plymouth Marine Laboratory, Uk, 2001.

DIONNE, J. C. Towards a more adequate definition of the St. Lawrence estuary. Zeitschr. F. Geomorfology, v. 7, n. 1, p. 36-44, 1963.

ELDSON, T.S. et al. Extensive drought negates influence on nutrients and water quality in estuaries. Science of the total environmental, v. 407, p. 3033-3043, 2009.

EPAGRI. Sintese anual da agricultura de Santa Catarina. Florianópolis: EPAGRI/CEPA, 2012.

IBGE -Instituto Brasileiro de Geografia e estatística.2013. Cidades. Disponível em http://www.cidades.ibge.gov.br/xtras/ home.php>. Acesso: maio de 2013

KAISER, D. et al. Natural and human influences on nutrient transport throught a small subtropical Chinese estuary. Science of the total environment, v. 450-451, p. 92-107, 2013.

MIRANDA, L. B.; CASTRO, B. M.; KJERFVE, B. Princípios de oceanografia Física dos estuários, 2002.

MOURA, L.H.A; BOAVENTURA, G.R.; PINELLI, Marcelo Pedrosa. A qualidade de água como indicador de uso e ocupação do solo: Bacia do Gama-Distrito Federal. Quimica Nova, São Paulo, v. 33, n. 1, p.97-103, 2010.

MUSTAPHA, A.; ARIS, A. Z. Spatial aspect of surface water quality using chemotric analysis. Journal of applied science $s$ in environmental anitation, Jakarta, v.6, n.4 p. 411-426, 2011. 
PEREIRA FILHO, et al. Estuário do Rio Camboriú-SC: Variação intramareal e transporte residual de nutrientes, COP e Clorofila-a em condições de quadratura e sizígia. Notas Téc. Facimar, v.6, p. 137-151, 2002.

PEREIRA FILHO, J.; SPILLERE, L. C.; SCHETTTINI, A. C. Itajaí-açu riverestuary (Santa Catarina, Brazil): Preliminary Budget for dissolvedinorganic nutrientes. Journal of coastal Research, $\mathrm{p}$. 702-206, 2006.

PEREIRA FILHO, et al. Spatial changes in the water quality of Itajaí-açu fluvial-stuarine system, Santa Catarina. Annals of the Brazilian Academy of Sciences, v.82, n.4, p. 963-982, 2010.

RÖRIG, L. R. Usos Múltiplos e Qualidade das Águas da Bacia do Baixo Itajai- $A c ̧$, SC: Elementos para Um Gerenciamento Integrado. 2005. 295p. Tese (Doutorado em Ecologia e Recursos Naturais), Universidade Federal de São Carlos, São Paulo, 2005.

SCHAFFELKE, Britta et al. Water quality in the inshore Great Barrier Reef lagoon: Implications for long-term monitoring and management. Marine Pollution Bulletin, p. 1-10, 2011.

SCHETTINI, C. A. F. Caracterização física do estuário do Rio Itajaí-açu, SC. Revista Brasileira de Recursos Hídricos. v.7, n.1, p. 123-142, 2002.

SCHETTINI, C.A.F.; TRUCOLLO, E.C. Circulação do baixo estuário do Rio Itajaí. In: BRANCO, J. O.; BRANCO, M.J.M.; BELLOTTO, V.R. (Orgs). Estuário do Rio Itajai-açu, Santa Catarina: caracterização ambiental e alterações antrópicas. Itajaí: UNIVALI, Cap. 1, 2009. p. 23-26.

SILVA, D. D. C.; PEREIRA FILHO, J. Qualidade Química da água em função de seu uso na rizicultura irrigada na região do baixo estuário do Rio Itajaí. Revista de estudos ambientais, v.12, n.2, p. 26-37, 2010.

SIGNORIN, M.; PEREIRA FILHO, J.; DELFIM, R.; SCHETTINI, C. A. F. Hidrodinâmica e nutrientes dissolvidos no estuário do Rio Perequê, SC. Braz. J. Aquatic. Sci. Technol, v. 14 (2), p. 13-21, 2010.

STRICKLAND, J.D.; PARSONS, T.R. A Practical Handbook of Seawater Analysis. Fish. Res. Board. Can. Bull. p.310, 1972.

VANZELA, L. S.; HERNANDEZ, F. B. T.; FRANCO, R. A. M. Influência do uso e ocupação do solo nos recursos hídricos do córrego Três Barras-Marinópolis. Revista Brasileira de Engenharia Agricola e Ambiental, v.14, n. 1, p.55-64, 2010.

XU, H. S.; XU, Z. X.; WU, W.; TANG, F. F. Assessment and spatiotemporal variation analysis of water Quality in the Zhangweinan river basin, China. Procedia Environmental Sciences, v.13, p. 1641-1652, 2012. 